\title{
Unwanted Diagnosis of a Subcutaneous Swelling
}

Indira Ramasamy ${ }^{1}$, Ashok Kumar Sahoo ${ }^{1}$, Harish Goutham Medapati ${ }^{1,2}$, TP Elamurugan ${ }^{3}$, Vishnu Prasad Nelamangala Ramakrishnaiah ${ }^{3}$

1. Surgery, Jawaharlal Institute of Postgraduate Medical Education \& Research, Puducherry, IND 2. Surgical Gastroenterology, Government Medical College, Srinagar, IND 3. Surgery, Jawaharlal Institute of Postgraduate Medical Education and Research, Puducherry, IND

Corresponding author: TP Elamurugan, elamurugantp@gmail.com

\begin{abstract}
Subcutaneous swelling is one of the common cases seen in surgical practice. The pathology of the subcutaneous swellings is varied ranging from epidermal inclusion cyst to malignant swelling. Fungal infections producing subcutaneous swelling are relatively rare. They occur in immunocompromised patients. We report a case of phaeohyphomycosis (PHM) which is characterized by the presence of pseudohyphae, hyphae, brown yeast-like cells, and melanin in their cell walls, presenting as subcutaneous swelling.
\end{abstract}

A 34-year-old male presented with a swelling over the anterior aspect of left knee joint for three months, which was initially painless. He gave a history of purulent discharge from the swelling 20 days back. He was a known case of myasthenia gravis on regular treatment with steroids. On examination, the swelling was firm, nontender, and mobile in subcutaneous plane. The skin over the swelling showed a healed puckered scar, fine needle aspiration cytology (FNAC) of the swelling showed slender, septate hyphae with variable branching bulbous ends, and few of the hyphae showed pigmentation morphologically suggestive of PHM. The swelling was excised with clear margin.

Subcutaneous mycosis is common in tropical and subtropical countries like India. Strong suspicion of this diagnosis is warranted especially in immunocompromised patients. Surgical excision is the treatment of choice to achieve early cure.

Received 04/27/2020

Review began 05/07/2020 Review ended 05/13/2020 Published 05/15/2020

๑) Copyright 2020

Ramasamy et al. This is an open access article distributed under the terms of the Creative Commons Attribution License CC-BY 4.0., which permits unrestricted use, distribution, and reproduction in any medium, provided the original author and source are credited.
Categories: Pathology, Radiology, General Surgery

Keywords: pseudohyphae, epidermal inclusion cyst, melanin, immunocompromised, histopathology

\section{Introduction}

Any fungus in tissue with pseudohyphae, hyphae, brown yeast-like cells, or a combination of these forms is well described under term phaeohyphomycosis (PHM) [1]. It is a relatively new term introduced by Ajello in 1974 [2]. These organisms are characterized by the presence of melanin in their cell walls, which is a prime virulent factor in these patients [3]. At least 60 genera and 109 species of fungi are found to cause PHM. Exophiala spinifera, Wangiella spinifera, Phialophora spinifera, and Bipolaris spinifera are most frequently encountered etiologic agents [4]. Although the fungi causing PHM are found across the world, they are more commonly encountered in tropical and subtropical areas [5]. PHM is found to occur in both

immunocompromised and immunocompetent persons, but more frequent in immunocompromised patients. Post organ transplantation, cancer, leukemia, prolonged hospitalization, and corticosteroid therapy are predisposing factors [6,7]. PHM can be classified based on the site of localization into superficial, cutaneous and corneal, subcutaneous, and systemic [6]. This present case falls in the subtype of subcutaneous PHM in a patient on corticosteroids.

\section{Case Presentation}

A 34-year-old male presented with complaints of swelling on the anterior aspect of the left knee joint for three months. It was insidious in onset and slowly progressively increasing in size. The swelling has been associated with moderate dull aching pain for 10 days. Swelling had ruptured 20 days before presentation with pus discharge, but there was no decrease in the size of the swelling. He gave no history of fever or any complaints in movements at the knee joint. The patient was diagnosed as a case of myasthenia gravis, and he has been on steroids since then. The patient had also developed steroid-induced diabetes mellitus. The patient was admitted with complaints of weakness of bilateral upper and lower limbs. On examination, there was a swelling on the right knee joint about $15 \times 10 \mathrm{~cm}$ in size in the subcutaneous plane, and also three more swellings of maximum size $4 \times 5 \mathrm{~cm}$ in the subcutaneous plane in the anterolateral aspect of the upper two-third of the right leg (Figure 1). 


\section{Cureus}

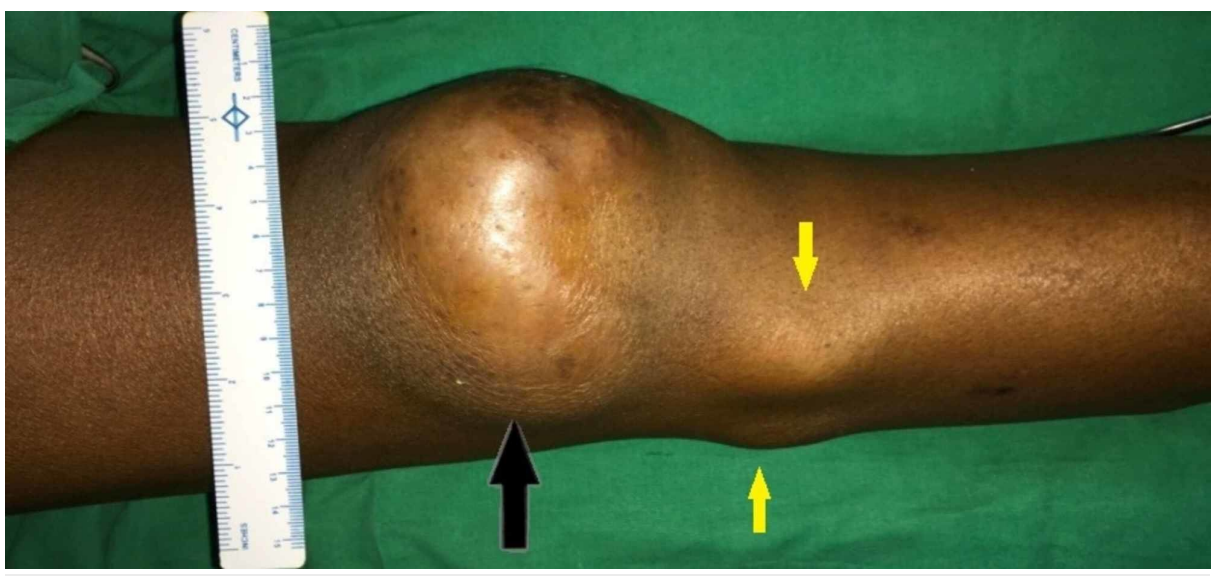

FIGURE 1: A bigger swelling on the right knee joint (black arrow) and other small swellings (yellow arrows) in the subcutaneous plane in the right leg

The patient was evaluated. Fine needle aspiration cytology (FNAC) of the swelling showed sheets of neutrophils in a necrotic background. There were many fungal organisms, which are slender, septate hyphae with variable branching bulbous ends. A few of the hyphae had pigmentation morphologically suggestive of PHM (Figure 2).

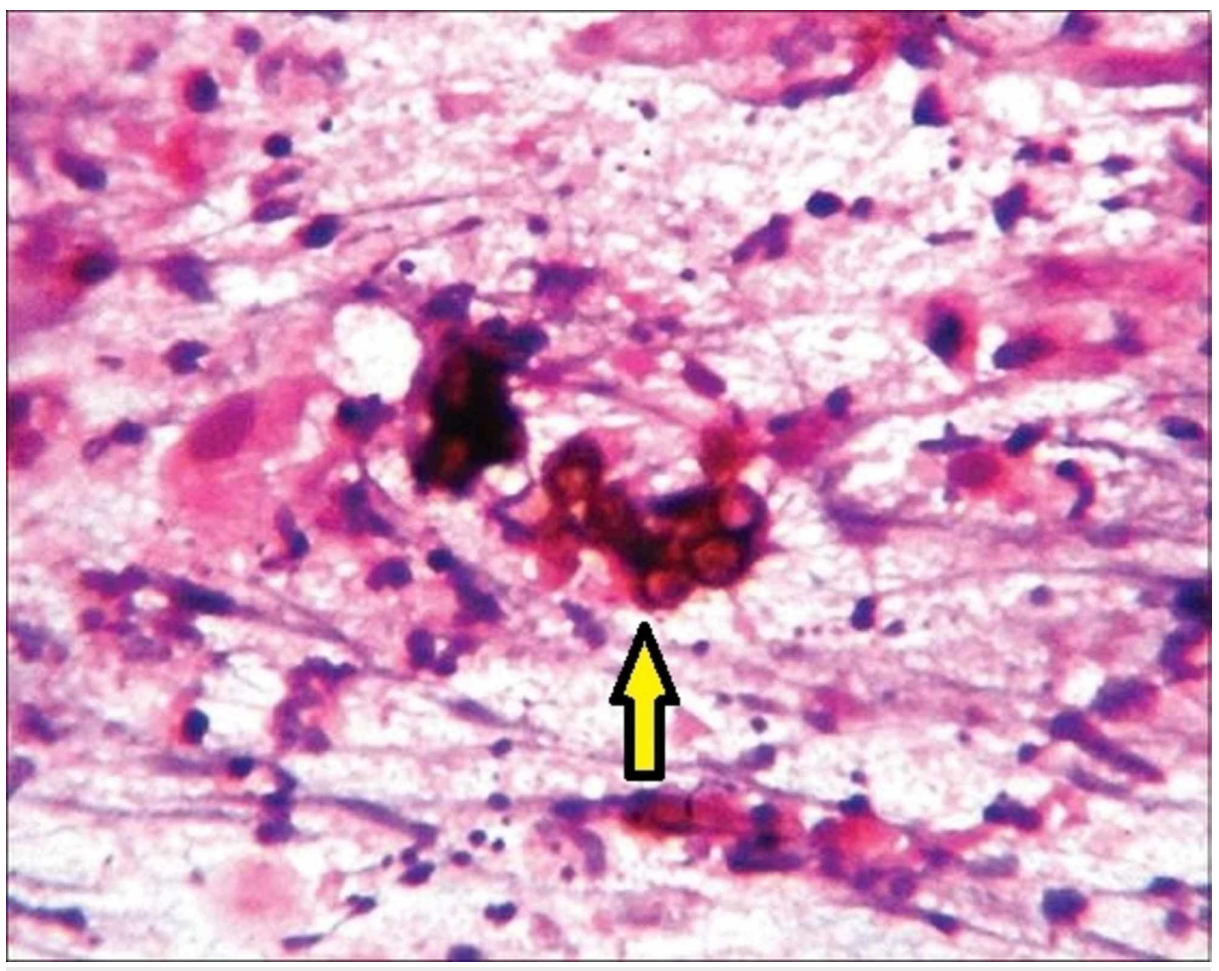

FIGURE 2: Fine needle aspiration cytology of the swelling showing fungal organisms with few of the hyphae having pigmentation morphologically suggestive of phaeohyphomycosis (yellow arrow)

Periodic acid-Schiff (PAS) stain had highlighted the fungal organism. MRI of the right lower limb was done, which showed a hypoechoic cystic loculated lesion in the subcutaneous plane with no involvement of the underlying knee joint (Figures 3, 4). 


\section{Cureus}

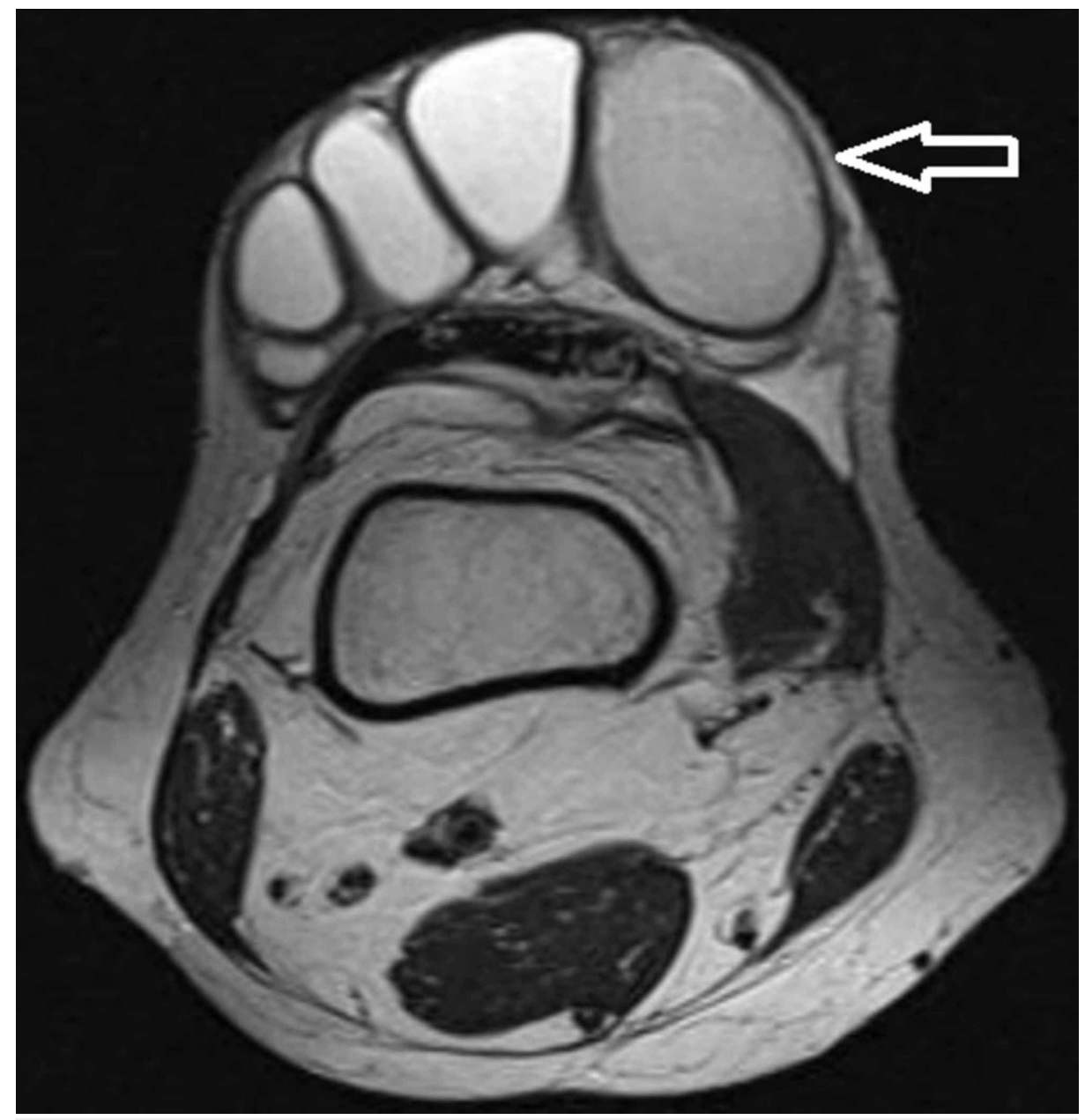

FIGURE 3: MRI of the right knee (transverse plane) showing hypoechoic cystic loculated lesion in subcutaneous plane (arrow) 


\section{Cureus}

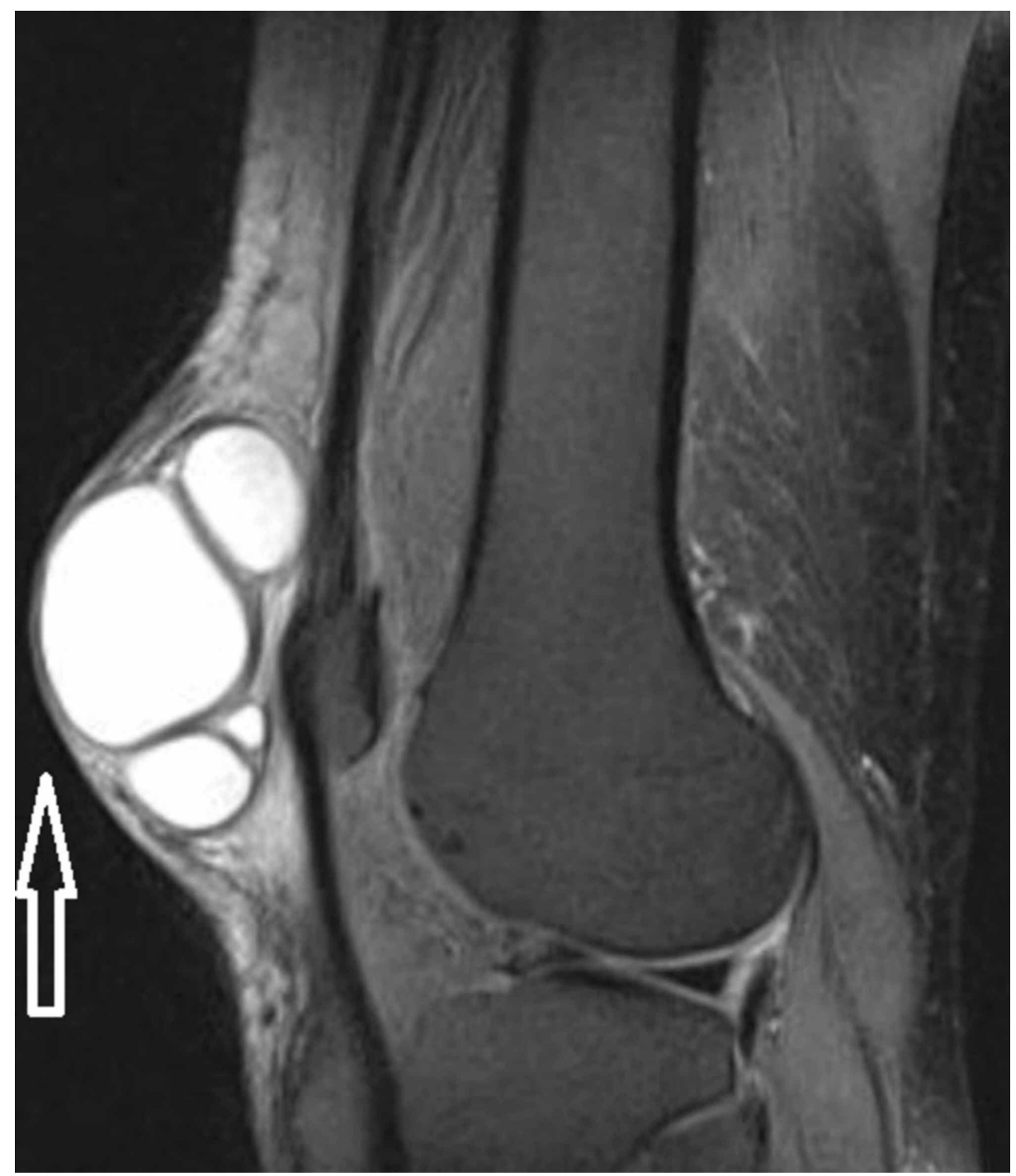

FIGURE 4: MRI of the right knee (coronal view) showing hypoechoic cystic loculated lesion in subcutaneous plane (arrow)

The patient was optimized for surgery and excision of the right knee and right leg swellings was done under spinal anesthesia (Figure 5). 


\section{Cureus}

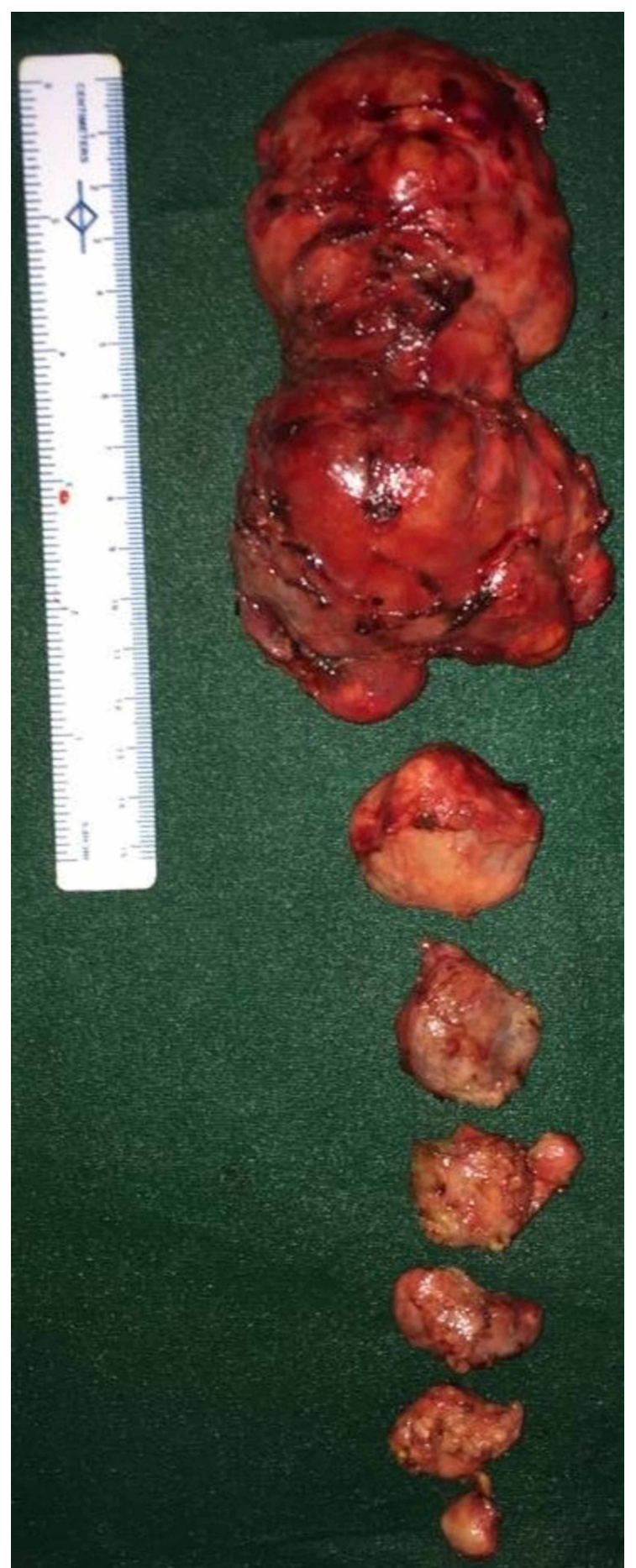

\section{FIGURE 5: Excised specimen}

The postoperative period was uneventful, and the patient was discharged. Surgical site healed well and sutures were removed on postop day 7 .

\section{Discussion}

Subcutaneous mycoses refer to a heterogeneous group of diseases caused by a wide variety of fungi that invade the cutaneous and subcutaneous tissue after traumatic implantation and are common in tropical and subtropical countries like India. It comprises of zygomycosis, PHM, hylohyphomycosis, mycetoma, chromoblastomycosis, sporotrichosis, lobomycosis, and rhinosporidiosis [8]. Manifestations of subcutaneous myocosis are varied and present as a cyst, ulcer, scaly lesion, verrucous growth, warty plaque, abscess, keratotic macerated lesions, and subcutaneous nodular lesions. Of the different types of subcutaneous mycosis chromoblastomycosis, PHM and eumecotic mycetoma comprise dematiaceous fungi that are characterized by their dark pigmentation due to deposition of melanin in their cell wall [9]. 
Phaeohyphomycosis, a relatively new term introduced by Ajello in 1974, is caused by 109 species of fungi which are classified into 60 genera, of which commonly associated include Exophiala, Phialophora, Cladosporium, Curvularia, Fonsecaea, and Alternaria [2,10]. PHM can be classified into five types: (i) superficial, black piedra and tinea nigra; (ii) cutaneous: dermatomycosis and onychomycosis; (iii) mycotic keratitis; (iv) subcutaneous; and (v) invasive, systemic, and cerebral [6,11,12]. Of these, subcutaneous PHM is the most common type which clinically present as papulonodules, cysts, or abscesses [9]. It clinically presents as a painless single subcutaneous cyst and rarely as multiple cysts; the skin surface is smooth and uninvolved. These lesions average about $2.5 \mathrm{~cm}$ in size and commonly noted in the extremities [8]. PHM must be differentiated from other conditions such as chromoblastomycosis, mycetoma, ganglion cyst, epidermal inclusion cyst, baker's cyst, foreign body granuloma, erythema nodosum, lipoma, and neurofibromas; this may be done with the assessment of clinical presentation followed by histopathology and culture sensitivity [9]. Histopathology of PHM shows inflammatory cells along with brown pigmented septate hyphae with acute angle branching. Hyphae measures 2-6 $\mu \mathrm{m}$ wide and they constrict at their prominent septations. Fontana-Masson staining demonstrates the presence of melanin; GomoriMethenamine Silver and PAS stains also help in identifying the fungal wall $[8,10]$. However, the antifungal agents, including flucytosine and itraconazole, appear to be effective treatments for patients with subcutaneous PHM [13]. Surgical excision of subcutaneous PHM is a widely accepted management for curative intent [6].

\section{Conclusions}

Subcutaneous mycosis is common in tropical and subtropical countries like India. Strong suspicion of this diagnosis is warranted especially in immunocompromised patients. Histopathological study is the only way to diagnose a suspected case. The characteristics of the fungi can be identified using different types of stains. Antifungals can be used to alleviate the symptoms but rarely it cures the disease. Surgical excision is the treatment of choice to achieve early cure.

\section{Additional Information \\ Disclosures}

Human subjects: Consent was obtained by all participants in this study. Conflicts of interest: In compliance with the ICMJE uniform disclosure form, all authors declare the following: Payment/services info: All authors have declared that no financial support was received from any organization for the submitted work. Financial relationships: All authors have declared that they have no financial relationships at present or within the previous three years with any organizations that might have an interest in the submitted work. Other relationships: All authors have declared that there are no other relationships or activities that could appear to have influenced the submitted work.

\section{References}

1. Ge H, Pan M, Chen G, Liu X, Shi T, Zhang F: The first case of cutaneous phaeohyphomycosis caused by Bipolaris spicifera in Northern China: a case report. Exp Ther Med. 2017, 14:1875-1878. 10.3892/etm.2017.4765

2. Ajello L, Georg LK, Steigbigel RT, Wang CJ: A case of phaeohyphomycosis caused by a new species of Phialophora. Mycologia. 1974, 66:490-498.

3. Jacobson ES: Pathogenic roles for fungal melanins. Clin Microbiol Rev. 2000, 13:708-717. 10.1128/cmr.13.4.708-717.2000

4. Brandt ME, Warnock DW: Epidemiology, clinical manifestations, and therapy of infections caused by dematiaceous fungi. J Chemother. 2003, 15:36-47. 10.1179/joc.2003.15.Supplement-2.36

5. Adam RD, Paquin ML, Petersen EA, et al.: Phaeohyphomycosis caused by the fungal genera Bipolaris and Exserohilum. A report of 9 cases and review of the literature. Medicine. 1986, 65:203-217. 10.1097/00005792-198607000-00001

6. Isa-Isa R, García C, Isa M, Arenas R: Subcutaneous phaeohyphomycosis (mycotic cyst). Clin Dermatol. 2012, 30:425-431. 10.1016/j.clindermatol.2011.09.015

7. Matsumoto T, Ajello L, Matsuda T, Szaniszlo PJ, Walsh TJ: Developments in hyalohyphomycosis and phaeohyphomycosis. J Med Vet Mycol. 1994, 32:329-349. 10.1080/02681219480000951

8. Priyadharshini G, Varghese RG, Phansalkar M, Ramdas A, Authy K, Thangiah G: Subcutaneous fungal cyst masquerading as benign lesions: a series of eight cases. J Clin Diagn Res. 2015, 9:1-4. 10.7860/JCDR/2015/14157.6637

9. Abraham, LK, Joseph E, Thomas S, Matthai A: Subcutaneous phaeohyphomycosis: a clinicopathological study. Int Surg J. 2014, 1:140-143.

10. Sharma NL, Mahajan V, Sharma RC, Sharma A: Subcutaneous pheohyphomycosis in India: a case report and review. Int J Dermatol. 2002, 41:16-20. 10.1046/j.1365-4362.2002.01337.x

11. Rippon JW : Medical Mycology: The Pathogenic Fungi and the Pathogenic Actinomycetes . W. B. Saunders Company-Harcourt Brace Jovanovich. W. B. Saunders Company-Harcourt Brace Jovanovich, Philadelphia, PA; 1990. 30:463-463. 10.1002/jobm.3620300624

12. McGinnis MR: Chromoblastomycosis and phaeohyphomycosis: new concepts, diagnosis, and mycology . J Am Acad Dermatol. 1983, 8:1-16. 10.1016/s0190-9622(83)70001-0

13. da Cunha KC, Sutton DA, Fothergill AW, et al.: Diversity of Bipolaris species in clinical samples in the United States and their antifungal susceptibility profiles. J Clin Microbiol. 2012, 50:4061-4066. 10.1128/JCM.01965-12 